\title{
Educação para a sustentabilidade: entre a vida na escola e a escola da vida
}

\section{Education for sustainability: between school life and the school of life}

\author{
Educación para la sostenibilidad: entre la vida \\ escolar y la escuela de la vida
}

Ricardo Vieira ${ }^{1}$

Ana Maria Vieira ${ }^{1}$

José Carlos Marques ${ }^{1}$

DOI: http://dx.doi.org/10.20435/serie-estudos.v26i57.1555

\begin{abstract}
Resumo: Neste texto, apresentamos alguns dados de uma investigação em curso cujo objetivo principal passa por entender as perceções e práticas que pessoas de várias faixas etárias possuem relativamente a questões de sustentabilidade. Desenvolvemos, inicialmente, uma abordagem teórica sobre a sustentabilidade no âmbito dos Objetivos de Desenvolvimento Sustentável (ODS), das Nações Unidas (CONSELHO EMPRESARIAL PARA O DESENVOLVIMENTO SUSTENTÁVEL [BCSD], 2021). Em termos empíricos, entrevistámos quatro sujeitos com as seguintes idades: 15, 22, 61 e 70 anos. Posteriormente à transcrição das entrevistas, fizemos uma análise comparativa das vozes captadas a propósito da importância que atribuem às práticas de sustentabilidade. Tentamos, assim, perceber de que forma a idade e o contexto sociocultural dessas pessoas influenciam as práticas e perceções que elas possuem sobre o tema da sustentabilidade.
\end{abstract}

Palavras-chave: sustentabilidade; objetivos de desenvolvimento sustentável; educação para a sustentabilidade.

Abstract: In this text, we present some data from an ongoing investigation whose main objective is to understand the perceptions and practices that people of various age groups have regarding sustainability issues. We initially developed a theoretical approach to sustainability within the scope of the United Nations' Sustainable Development Goals (SDGs) (CONSELHO EMPRESARIAL PARA O DESENVOLVIMENTO SUSTENTÁVEL [BCSD], 2021). In empirical terms, we interviewed four subjects with the following ages: 15, 22, 61, and 70 years old. After the transcription of the interviews, we made a comparative analysis of the voices captured regarding the importance they attach to sustainability practices. Thus, we try to understand how the age and the socio-cultural context of these people influence their practices and perceptions about the theme of sustainability.

\footnotetext{
${ }^{1}$ Escola Superior de Educação do Instituto Politécnico de Leiria (ESECS.IPLeiria); Centro Interdisciplinar de Ciências Sociais da Universidade Nova de Lisboa (CICS.NOVA.IPLeiria), Leiria, Portugal.
} 
Keywords: sustainability; sustainable development goals; education for sustainability.

Resumen: En este texto, presentamos algunos datos de una investigación en curso cuyo principal objetivo es comprender las percepciones y prácticas que tienen las personas de diversos grupos de edad sobre los temas de sustentabilidad. Inicialmente, desarrollamos un enfoque teórico de la sostenibilidad dentro del alcance de los Objetivos de Desarrollo Sostenible (ODS) de las Naciones Unidas (CONSELHO EMPRESARIAL PARA O DESENVOLVIMENTO SUSTENTÁVEL [BCSD], 2021). En términos empíricos, entrevistamos a cuatro sujetos con las siguientes edades: 15, 22, 61 y 70 años. Luego de la transcripción de las entrevistas, realizamos un análisis comparativo de las voces captadas sobre la importancia que le dan a las prácticas de sustentabilidad. Así, tratamos de comprender cómo la edad y el contexto sociocultural de estas personas influyen en sus prácticas y percepciones sobre el tema de la sostenibilidad.

Palabras clave: sostenibilidad; objetivos de desarrollo sostenible; educación para la sostenibilidad.

\section{INTRODUÇÃO}

A Sustentabilidade é uma temática que tem vindo a ganhar espaço na discussão pública, na escola e fora da escola. A escola não se pode limitar única e exclusivamente à transmissão de saberes cognitivos. Deve preocupar-se também com a formação dos jovens para o exercício de uma cidadania ativa, responsável e esclarecida. Nesta linha, a educação ambiental é também educação social. Ela é uma parte importante da educação para a cidadania.

Assim, este tema apela a uma atenção especial, uma vez que cada vez mais se tornam urgentes as questões ambientais, a redução do consumismo e uma atenção focalizada na saúde humana. É fundamental uma educação para o ambiente, para a reutilização, reciclagens e sustentabilidade. Isto implica um conjunto de competências fundamentais para responder aos desafios que a educação do século XXI no coloca (DELORS, 1996; SUA PESQUISA, 2021).

Este texto resulta de uma investigação em curso, na Escola Superior de Educação do Instituto Politécnico de Leiria (ESECS.IPLeiria) e no Centro Interdisciplinar de Ciências Sociais da Universidade Nova de Lisboa, Polo de Leiria (CICS.NOVA.IPLeiria), e tem como objetivo fundamental compreender as perceções, ideias e práticas exercidas pelos sujeitos entrevistados, relativamente às práticas de sustentabilidade.

A investigação adota uma metodologia compreensiva, de análise exploratória e qualitativa, assentando em entrevistas abertas, dando espaço para a escuta e a exposição do pensamento dos inquiridos. 


\section{ENQUADRAMENTO TEÓRICO}

Falar de sustentabilidade é pensar em formas de satisfazer as necessidades atuais sem comprometer as gerações futuras. Há, assim, um relacionamento grande com a problemática do crescimento/desenvolvimento que deveria ocorrer sem prejudicar o ambiente.

A escassez dos recursos naturais, os impactos da ação humana nos ecossistemas, a desigualdade social, a discriminação e a falta de princípios éticos na gestão organizacional são, por vezes, espelhos da não sustentabilidade.

Para potenciar a sustentabilidade é fundamental apostar em medidas de reciclagem e de reutilização que não ponham em causa os recursos para as gerações futuras. A exploração dos recursos minerais de forma planeada e moderada, o uso de fontes de energia renovável com o objetivo de minimizar o consumo de combustíveis fósseis, a promoção de atitudes ligadas à reciclagem e à reutilização, consumo, poupança e preservação das águas reduzindo o desperdício são bons exemplos dessas boas práticas (SCHMIDT; GUERRA, 2013).

O planeta azul é cada vez mais confrontado com ataques de dimensão global, simultaneamente de âmbito económico, social, cultural e ambiental. Daí a necessidade de uma aposta global no uso de energias limpas, na reciclagem, na compostagem, na economia de água e na preservação do ambiente como os pilares fundamentais da sustentabilidade do planeta. E daí a aposta numa educação ambiental (SCHMIDT; NAVE; GUERRA, 2010) e intrassocial (TILBURY, 2004).

De acordo com o Conselho Empresarial para o Desenvolvimento Sustentável (BCSD, 2021), a Agenda 2030 para o Desenvolvimento Sustentável da Organização das Nações Unidas (ONU) é composta por 17 Objetivos de Desenvolvimento Sustentável (ODS) e foi aprovada em setembro de 2015 por 193 membros, proveniente da cooperação entre os governos e os cidadãos de todo o mundo com a finalidade de apresentar um novo modelo global para pôr fim à pobreza, promover a prosperidade, o bem-estar e a qualidade de vida para salvaguardar o ambiente e contrariar as alterações climáticas.

Foram definidos como ODS os seguintes: erradicar a pobreza; erradicar a fome; saúde de qualidade; educação de qualidade; igualdade de género; água e saneamento; energias renováveis e acessíveis; trabalho digno e crescimento económico; indústria, inovação e infraestruturas; reduzir as desigualdades; cidades e comunidades sustentáveis; produção e consumo sustentáveis; combater as 
alterações climáticas; oceanos, mares e recursos marinhos; ecossistemas terrestres e biodiversidade; paz e justiça; parcerias para o desenvolvimento (BCSD, 2021). Estes 17 objetivos são ideias-temas que a todas e todos dizem respeito. São da responsabilidade de todos, pois são fundamentais para uma sociedade moderna, equilibrada e harmoniosa, com a capacidade de criar emprego e riqueza e, ao mesmo tempo, respeitar a Natureza e os Direitos Humanos.

Os Objetivos do Desenvolvimento Sustentável relacionam-se diretamente com as entrevistas realizadas aos quatro sujeitos que apresentamos abaixo, na medida em que procurámos apurar as suas perceções e práticas de sustentabilidade.

O Desenvolvimento Sustentável constitui hoje um dos problemas contemporâneos mais discutidos e referenciados. A título de exemplo, as alterações climáticas e a decisão de optar por um estilo de vida cada vez mais sustentável e ecológico são das principais preocupações da sociedade atual.

Apesar de todas estas preocupações, as culturas hegemónicas continuam a caracterizar-se muito pelo excesso de consumos diversos e pelo comodismo em larga escala. O estilo de vida destas sociedades tem conduzido à produção em massa e ao esgotamento de muitos recursos, acarretando uma destruição gradual do planeta.

Eé por essa necessidade de mudança profunda, e tendo por base os resultados positivos e as melhorias alcançadas com os Objetivos de Desenvolvimento do Milénio (ODM), em 2015, que se estabeleceram esses 17 novos objetivos, designados como ODS, dando origem à Agenda 2030 para o Desenvolvimento Sustentável, assinada por 193 países e com 169 metas definidas, para alcançar até ao ano de 2030. Este conjunto de objetivos é mais ambicioso, comparativamente com os ODM, sendo que pretendem abordar mais dimensões relacionadas com o desenvolvimento sustentável. Segundo o Fundo das Nações Unidas para a Infância (UNICEF),

Os ODS representam um plano de ação global para eliminar a pobreza extrema e a fome, oferecer educação de qualidade ao longo da vida para todos, proteger o planeta e promover sociedades pacíficas e inclusivas até 2030. Estão baseados nos compromissos para as crianças e os adolescentes nas áreas de pobreza, nutrição, saúde, educação, água e saneamento e igualdade de gênero contidos nos precursores dos ODS, os Objetivos de Desenvolvimento do Milênio. Os ODS também incluem novos objetivos e metas relacionados à proteção da criança e do adolescente, à educação infantil e à redução das desigualdades. (UNICEF, s.d.). 
Tendo por base o objetivo fundamental deste trabalho, urge aprofundar alguns conceitos, designadamente o conceito de Desenvolvimento Sustentável (DS) e o de Sustentabilidade.

Segundo BAKER (2006), as preocupações com a sustentabilidade surgem associadas ao aumento populacional, nos séculos XVIII e XIX, expandindo-se no século seguinte devido aos impactos ambientais provocados pelo desenvolvimento industrial. As preocupações com a degradação ambiental e com a necessidade de preservar as condições de vida na terra, são, contudo, mais antigas, sendo possível identificar formas de "[...] com cuidado, diminuir os efeitos perversos" (CATO; VARRO, 1954 apud DU PISANI, 2006, p. 85) das atividades humanas desde, pelo menos, o século primeiro da Era Comum. As preocupações relativas ao uso excessivo da floresta, no século XVI, na Alemanha (DU PISANI, 2006), ao desequilíbrio entre população e recursos, iniciadas com o ensaio de Malthus sobre os princípios da população e a melhoria futura da sociedade, no final do século XVIII (MALTHUS, 1798), e, de forma mais próxima, à crescente carbonização decorrente da aceleração do processo de industrialização, consumismo e crescimento demográfico que define uma nova época geológica designada por alguns por Antropoceno (CRUTZEN; STOERMER, 2000) constituem-se como marcos fundamentais na evolução do conceito, políticas e práticas associadas à sustentabilidade. A preocupação em torno da sustentabilidade associa-se, desta forma, ao desenvolvimento económico e social da humanidade.

O conceito tem sido usado no sentido de apontar para os efeitos da ação humana sobre os recursos naturais e para assinalar o receio de as gerações presentes e futuras poderem vir a estar privadas destes mesmos recursos. Conforme menciona o Relatório Brundtland, trata-se de um conceito delineado pela visão antropocêntrica, "[...] uma vez que não atribui à natureza um valor intrínseco, mas meramente instrumental para os seres humanos" (UNITED NATIONS [UN], 1987, tradução nossa), reforçando a preservação da natureza em benefício das gerações futuras, pela visão otimista, colocando esperança na coletividade humana, conduzindo à construção de um futuro sustentável.

Na linha do Relatório suprarreferido, é

O desenvolvimento que satisfaz as necessidades do presente sem comprometer a capacidade das gerações futuras satisfazerem as suas próprias necessidades, garantindo o equilíbrio entre o crescimento económico, o cuidado com o ambiente e o bem-estar social. (LISBOA, s.d). 
Por conseguinte, a sustentabilidade refere-se a uma conceção sistémica resultante e refletida nas atitudes humanas e organizações, estando focalizada na sobrevivência do planeta. Contudo, "[...] é um conjunto de ideias, estratégias e atitudes ecologicamente corretas, economicamente viáveis, socialmente justas e culturalmente diversas" (LISBOA, s.d.).

Assim, a Sustentabilidade Ambiental ou Ecológica diz respeito ao uso consciente dos recursos naturais, ou seja, à preservação e manutenção do ambiente, de forma que as gerações futuras não sejam afetadas. Já a Sustentabilidade Empresarial, visa ser sustentável e trabalhar em prol do planeta, mantendo sempre a sua responsabilidade social.

\section{METOdOLOGIA E PÚBLICO-ALVO}

Apresentada a problemática científica que suporta a investigação em curso, sobre perceções e práticas de sustentabilidade, e considerando os objetivos referidos, a técnica eleita nesta fase foi a entrevista aberta, de caráter exploratório, sendo que esta nos permite obter informações e momentos de reflexão muito ricos e matizados, possibilitando que o entrevistado exponha os seus pensamentos de forma naturalística.

O público-alvo com que iniciámos esta pesquisa foi diversificado, tendo em conta idades, género e escolaridade. Usando fundamentalmente uma metodologia assente em entrevistas abertas, privilegiando a escuta ativa sobre os interesses e práticas de sustentabilidade da Brigite (15 anos, aluna do ensino secundário), da Vera (22 anos, estudante do ensino superior), do Abel (mecânico, 61 anos) e do Mário (aposentado, 70 anos), recolhemos narrativas sobre as práticas e representações que apresentamos de seguida, essencialmente nas próprias palavras dos sujeitos investigados.

\section{VOZES QUE CLAMAM POR SUSTENTABILIDADE}

\subsection{Brigite}

A Brigite, 15 anos, aluna do ensino secundário, tem discurso fluido e estruturado sobre estas matérias, que faz questão de clarificar: "[...] não é só em questões do ambiente [...] mas também em questões de alimentação [...], tem a 
ver com o impacto nas pessoas... em termos de saúde humana... quando estamos a poluir o ar [...] também nos estamos a prejudicar a nós [...]" .

No que diz respeito à sustentabilidade e meio ambiente, refere que: "Se nós cuidarmos cada vez mais do nosso planeta, este também vai durar mais. Mas o problema é que nós não vamos reconhecer isso nos dias de hoje, mas sim daqui a uns anos, porque não tem que ver connosco mas sim com o nosso futuro [...]". As preocupações relativamente ao futuro ocupam um lugar central na reflexão da Brigite:

Sinceramente, tenho um bocado de medo do futuro, por exemplo, da minha geração, dos meus netos... Eu acho que se não começarmos agora a tratar dos problemas que se estão a começar a criar, acho que mais tarde não será a hora certa para remediar o que as nossas gerações prejudicaram!

Brigite estabelece uma diferença entre as práticas quotidianas que considera fáceis de implementar e as mais difíceis de pôr em prática. Quanto às mais fáceis, refere:

[...] não deitar lixo para o chão [...], reciclagem [...], diminuir o consumo de plásticos [...]"; "[...] plantar e consumir aquilo que plantamos [...]"; "[..] tomo banho mais rápido [...], ir buscar água à fonte [...], ir de autocarro para a escola [...], faço (trocas) de roupa ou dou [...]"; "[...] damos [comida] ao cão ou às galinhas [...], aproveitamos a água da chuva para regar [...].

E em relação às práticas mais difíceis, menciona: "[...] deixar de comer carne [...], podia andar de bicicleta ou a pé [...], mas [...] é impossível, porque vivo no campo, e tenho sempre de pegar no carro para ir à cidade, fazer compras ou assim...".

Questionada sobre a educação e sobre as referências biográficas e contextuais que poderão ter contribuído para estas preocupações, diz que

[...] veio através dos meus pais. [...]. Mas aquilo que tento praticar em casa é tomada de consciência da minha parte, [...], acho que cada vez mais nas escolas há essa consciencialização [...], considero importante de referir [...] as redes sociais... Nas redes sociais cada vez mais há bastante informação e tomadas de consciência, o que nos ensina também... [...]"; "dou como exemplo a minha escola [...] vemos muitas reportagens sobre a sustentabilidade [...].

Relativamente às outras faixas etárias, Brigite recorre ao conhecimento que tem das práticas dos seus avós e diz que

[...] os nossos avós [...] têm, sim, essas práticas, mas fazem-nas sem consciência que aquilo é bom para o meio ambiente... fazem-no porque foi incutido 
[...] por uma questão de economia [...], acho ser mais difícil consciencializá-los para a questão ambiental..."; "[...] as gerações mais novas estão mais preparadas para [...] a sustentabilidade [...], estamos mais consciencializados, mais informados [...].

Em termos de propostas de mudança, Brigite sonha com um futuro mais sustentável e defende que as políticas têm um papel muito importante no que que diz respeito à implementação de mais regras. Nesta linha, defende que é com pequenas ações que se vai construindo a diferença:

[...] terminaria com os caixotes de lixo gerais e colocaria apenas e só os contentores de reciclagem, em cada rua do país! [...] a criação de folhas recicláveis [...] eu acho que deviam inventar folhas que dessem para apagar tudo o que estava escrito, a caneta, para voltar a utilizar!

Para mim, a diferença está nas pequenas coisas... e nesta questão da sustentabilidade é igual. Mesmo que achemos que o que estamos a fazer seja mínimo, não!... É sempre algo que faz toda a diferença, e que se fizermos todos essa mesma coisa, com certeza que contribuirá de forma positiva para um mundo melhor!

\subsection{Vera}

A Vera, estudante do ensino superior, de 22 anos, diz que foi através da reflexão sobre o desperdício da alimentação que veio a desenvolver outras preocupações ambientais e de sustentabilidade global:

[...] o tema do ambiente, da sustentabilidade, da preocupação ambiental [...] nunca me interessei muito [...]. [...] o grande choque para mim, da sustentabilidade, foi mais a nivel da alimentação, que depois me puxou para outras realidades [...], vi um documentário, o "Cowspiracy" [...], aquilo foi um choque enorme! [...]. Percebi que tínhamos de fazer alguma coisa e que, pessoalmente, tinha de ter mais atenção ao que estava a fazer aqui neste mundo [...]. Então, para mim, a sustentabilidade é ter um modo de vida saudável que, por si só, engloba várias coisas, e que não prejudique o ambiente ao nivel da redução de plásticos, da redução do consumo de carne... foi aí que eu comecei o meu caminho na sustentabilidade.

A Vera acredita que a preocupação com o meio ambiente começa com cada indivíduo e suas práticas, designadamente com a reflexão sobre o consumo de plásticos e a consciência da importância de minimizar a pegada ambiental humana: 
[...] se formos à raiz da palavra... a sustentabilidade é um meio de manter algo, de forma contínua... de que modo é que isso reduz o impacto no meio ambiente!? [...]. Se tu reduzires o teu consumo de plástico vais ter um impacto, vais reduzir a tua pegada ambiental...; [...] se te preocupares com o meio ambiente, e quanto mais te preocupares com esse problema no geral, podes querer fazer a diferença, mas essa começa por ti! Começas por ter em atenção os teus hábitos e depois vais ao mais abrangente... Desta forma, estás-te a preocupar, não só contigo, mas também com os outros...

A partir de uma reflexão sobre a aposta nas compras online que a Pandemia Covid-19 estimulou, a Vera reflete depois sobre a complexidade do processo que vai do produtor ao consumidor e sobre a confusão entre instrução/moldagem e educação:

Nos supermercados, na alimentação não sustentável pagamos as embalagens, ou seja, vem do produtor para a fábrica, que embala, e depois vai para o supermercado, são três distribuidores diferentes, enquanto que na alimentação sustentável, nas lojas a granel, as pessoas veem o preço ao quilo e pensam "32€ o quilo?!".. claro! Mas nós nunca levamos um quilo de tempero, levamos 100/150 gramas e poupa-se imenso, porque levamos as nossas embalagens e pagamos só o preço do produto, não pagamos o preço da embalagem.

[...] há demasiada informação e as pessoas não sabem pelo que é que se devem guiar... A maior parte da informação não é correta ou induz-te em erro, [...] se ouvirmos falar nas redes sociais: "façam isto, façam aquilo..." [...] acaba por não ser uma educação... acaba por ser instrução! Tentam moldar-te e, a meu ver, esse não é o objetivo.

A propósito da transformação das suas práticas, entre diversos exemplos, apresenta o da substituição das garrafas de plástico por uma garrafa de vidro reutilizável, assim como a substituição das palhinhas de plástico pelas de inox:

[...] antigamente comprava imensas garrafas de água, todos os dias; hoje em dia já não compro garrafas de água, tenho uma garrafa de vidro que, quando quero utilizar, encho. Comprei palhinhas de inox, é um bem supérfluo, mas já não uso palhinhas de plástico. Ao nível da reciclagem, faço sempre reciclagem [...]. Não como carne nenhuma durante a semana, apenas como carne ao fim de semana, e se comer carne durante a semana é apenas de peru ou frango, prefiro a alternativa do peixe e tento sempre ver se consigo arranjar na minha zona ou com os meus vizinhos, caso seja possivel fazermos uma troca. [...] Antes deste segundo confinamento, tinha 
começado a ir a lojas de roupa em segunda mão, espantou-me o preço das peças e, por outro lado, saber que estava a dar uma segunda vida à roupa [...]. Ao nível de champôs, comprei um champô sólido, estou a tentar ter um champô sem embalagem, vou às lojas a granel, que têm imensa coisa, desde alimentos a produtos de higiene, basta levar os frascos e encher, como por exemplo o detergente para a máquina de lavar roupa... Quando sair da casa dos meus pais, estou a pensar em fazer uma horta e tentar ao máximo produzir algumas coisas para o meu dia a dia; o que não for possivel terei de comprar, mas sempre nesta ótica de ir ao produtor local, ao comércio local, não ir às grandes superfícies a não ser que seja mesmo necessário [...].

Referindo-se a práticas difíceis de mudar, no tocante à sustentabilidade, exemplifica dizendo que "[...] ainda tenho um grande passo a tomar ao nível do consumo de roupa, quero mesmo mudar isso [...]"; ; [...] eu moro longe de tudo, se eu quiser ir a algum sítio tenho de, inevitavelmente, levar o carro"; "[...] consigo dar as minhas caminhadas, passear o cão, e aí não utilizo o carro, mas para tudo o resto é necessário [...]".

Questionada sobre a construção da consciência ecológica que demonstra ter, não tem dúvidas em afirmar que tal resultou do contacto que passou a ter com pessoas vegetarianas. Como incidente crítico também construtor destas práticas e representações, assinala a importância de um documentário que visionou na escola, Cowspiracy: the Sustainability Secret:

[...] Só me comecei a interessar quando conheci o meu namorado, foi ele que me apresentou as pessoas que eram vegans ou vegetarianas e começaram- me a falar um bocadinho sobre a alimentação deles, a preocupação com o meio ambiente... e como tive mais contacto com essas pessoas, foi a partir daí que eu comecei a pensar [...]. No secundário vimos um documentário, o "Cowspiracy"... para mim, ver aquilo foi um choque enorme [...]. Lembrome que para mim foi mesmo impactante... depois informei-me e vi outros documentários... Depois a comunicação social divulgava cada vez mais os impactos ambientais e o que acontecia no meio ambiente, dos glaciares, da Amazónia... tudo isso fez-me pensar [...].

[...] num jantar, em 2015, [...] conversa puxa conversa, começámos a falar de temas como o veganismo e vegetarianismo, posteriormente sobre a sustentabilidade, [...] e partiu muito daí... A nível familiar, não houve nada que tivesse despertado este meu interesse, também um pouco derivado ao nível cultural [...]; se eu tivesse crescido numa família com um tipo de dieta, 
então talvez fosse geracional, mas não, a minha família é francesa, é tudo à base de massas. [...].

Relativamente à análise comparativa que faz sobre as temáticas da sustentabilidade entre pessoas de diversos níveis etários, Vera não tem dúvidas que

Os nossos avós... e eu vejo pela minha avó, que tinha nove filhos em casa... a principal preocupação dela era alimentá-los, primeiro. Não se pensava no meio ambiente como se pensa agora. [...]. A minha avó chegou-me a contar que no fim dos mercados apanhava a fruta do chão e as que estivessem em melhor estado era as que levava para fazer comida em casa. Se formos a ver, é sustentabilidade, porque é aproveitar, mas na consciência dela o que estava a fazer era assegurar necessidades básicas. Hoje em dia, há uma maior facilidade nisso, porque somos mais consciencializados desde novos para esta temática do meio ambiente e, portanto, mais cuidadosos com essas coisas. [...] Hoje em dia as condições de vida são melhores, a esperança média de vida também aumentou, e estes são fatores que contribuem para que possamos pensar nesta parte da sustentabilidade, uma vez que temos as nossas necessidades básicas satisfeitas, permitindo-nos passar às secundárias [...].

Quanto às políticas e às orientações da ODS, Vera refere que

Há imensa coisa que está a ir a favor do ambiente e da sustentabilidade, porém, considero que é muito bom mudar o todo, mas não é possível mudar o todo se não educamos, consciencializamos e sensibilizamos as pessoas particularmente. Está-se a implementar políticas a nível europeu - atenção, o que eu acho incrivel! -, está-se a fazer história, estamos a mudar o processo das coisas, mas, por outro lado, as pessoas vão fazer os mesmos erros, isto porque não são informadas o suficiente sobre isso. [...] Se olharmos para os países nórdicos, o nível de políticas que eles têm - sociais, educativas, ambientais - são incríveis, eles são o meu ideal, porque a taxa de criminalidade é reduzida, ao nível da educação têm um cuidado com o outro impressionante, igualmente com as políticas ambientais.

E acrescenta, a nível da construção de um futuro mais sustentável, que

[...] percebi que tínhamos de fazer alguma coisa e que eu, pessoalmente, tinha de ter mais atenção ao que estava a fazer aqui neste mundo, porque é o mundo onde nós vivemos, é o futuro que vamos deixar aos nossos filhos, netos e gerações futuras.

[...] é preciso trabalhar a nivel individual e da mentalidade dos portugueses. Considero que ainda há um longo caminho a percorrer e é aí que entra a 
parte da educação, educar as pessoas, mas não incutir, falar informalmente, como estamos a fazer hoje, sobre estes temas. [...] Se eu tivesse tido mais cedo alguém a ter a conversa que teve comigo naquele dia, mas numa escola, face a uma turma de 30 pessoas, mesmo que as 30 não mudassem de opinião, ficavam a conhecer, e se 10 dessas pessoas mudassem o seu hábito já era incrivel, e se em cada turma 10 pessoas mudam os seus hábitos, ou um pequeno hábito, já vale a pena esta parte educativa.

\subsection{Abel}

Abel tem 61anos e é mecânico. Refere, reiteradamente, nas narrativas construídas ao longo da entrevista como conversa (BURGUESS, 1997), que temos de "cuidar do meio ambiente" e da nossa alimentação.

Refletindo sobre a sustentabilidade e o meio ambiente, Abel concretiza, dizendo: "[...] a sustentabilidade [...] está direcionada ao meio ambiente... penso que será o nosso bem-estar, a nossa própria alimentação, tudo o que envolve resíduos, saber separá-los, saber cuidar deles, e assim sucessivamente...".

Abel sublinha preocupações com as práticas pouco ecológicas e pouco sustentáveis de muitas pessoas com quem interage, algumas ligadas à sua profissão de mecânico e ao futuro da sua própria família e da humanidade:

[...] centram-se em pensar no dia de amanhã, pensar no futuro, pensar que tenho os netos e depois bisnetos e temos de Ihes dar uma vida com um futuro risonho, um futuro feliz; [...] É muito triste, por exemplo, quando vamos fazer uma caminhada pelo campo, e encontramos sacos do lixo, pneus velhos, frigoríficos pela beira dos caminhos [...]; [...] Quando eu vou às peças, vejo lá muito consumidor final a comprar jerricans de óleo [...] a título de curiosidade pergunto-Ihes "vocês vão mudar o óleo do vosso carro e o que é que vão fazer ao óleo queimado?" respondem-me "voltamos a colocar dentro do jerricans e deixamos no contentor de lixo comum"... fico chocado! Por um lado, temos aqueles que contribuem para o bem-estar do ambiente e temos outros a poluir, as pessoas fazem o que querem.

Em relação às práticas que procura desenvolver para ser diferente dos que critica e para pensar mais no futuro do planeta, das pessoas, e na sustentabilidade, elenca diversas mudanças que operou em si e que poderão servir de inspiração a outras mudanças necessárias para uma vida mais sustentável, assente na reciclagem de inúmeras matérias: 
[...] eliminando tudo o que são lixos desnecessários, como pulverizações que se utilizam por vezes nas oficinas, vaporizações que vão para o ambiente, para a atmosfera [...]. No caso das embalagens de spray em lata [...] são todos amassados e enviados para a sucata de metal... separar os lixos uns dos outros [...]; cascas e frutas tentamos deixar apodrecer para depois cultivar o solo e fortalecer as próprias plantas... todos os alimentos que produzimos são consumidos em casa [...]; [...] aproveitamos estrumes dessas aves para meter na terra [...]. Sou caçador e, ao dar um tiro, apanho sempre o cartuxo vazio, porque sei que aquele cartuxo, para ser destruído, demora cerca de 800 anos [...]; [...] tenho dois tanques, de mil litros cada, onde vai ter toda a água que é recolhida pelos meus beirados... Desta forma, aproveito essas águas para lavar os canis dos meus cães, para regar as plantas, e até para lavar a minha oficina! [...]; [...] se vou numa reta e à distância vejo uma subida, tento dar velocidade ao carro para que chegue ao cimo da subida com a mesma velocidade com que vinha na reta. Desta forma, não tenho necessidade de colocar o carro em esforço, que, consequentemente, iria poluir mais e enviar mais gases para a atmosfera...

Abel fala-nos, também, das mudanças mais difíceis de pôr em prática, como é o caso da substituição dos sacos de plástico. Nas suas próprias palavras, "a redução do plástico vai ser um processo difícil para todos":

Os sacos de plástico [...] deveriam ser substituídos. Quando era miúdo, [...] o saco de papel [...] ia para o lixo [...], passado dois dias estava podre [...]; o saco de plástico podem-no colocar no lixo, fazer-lhe o que quiserem, que ele demora muitos anos para se deteriorar [....], para queimar vai sobrecarregar a nossa atmosfera com fumos e com poluições de plástico. [...] A redução do plástico acho que vai ser um processo difícil para todos, apesar de considerar ser um passo urgente. Mas, atenção... lembrem-se que o problema não está no plástico, mas sim na ação humana!

Fala-nos também da importância da Educação, que passa muito pela história de vida de cada um, na sua própria opinião. O trabalho na oficina de automóveis começou muito cedo na sua vida, e a regra de tudo ter de limpar no final do dia, essencialmente as manchas de óleo, para que não penetrassem no solo, é uma memória orientadora das suas práticas de hoje:

[...] comecei a trabalhar muito cedo [...]; baseando-me na minha aprendizagem no ramo automóvel, [...] o chão tinha de estar sempre limpo! Uma mancha de óleo e tínhamos que pegar num pano [...], para que não houvesse infiltrações de óleos no solo. Penso que, com os anos, vamos adquirindo 
determinadas experiências e acabamos por saber o que estamos a fazer de bom para o ambiente. [...]. Com o tempo e com os anos é que vamos ganhando noção das más práticas que tínhamos no passado, temos de as ir corrigindo ao longo do tempo.

Abel refere-se à mudança que observa nas práticas dos condutores que buscam a sua oficina. Os carros não vêm com tanto lixo. Há algumas preocupações com a reciclagem, e isso só pode resultar de uma nova visão do mundo, de responsabilidade social e de educação social e ambiental:

[...] antigamente os carros vinham para a oficina muito sujos e isso agora não acontece tanto, é muito raro [...], os condutores até têm um saco onde colocam os papéis de rebuçados, etc. [...]. Reparo que as pessoas têm uma maior atenção em não mandar um papel fora ou uma garrafa de plástico pelo vidro da janela.

Relativamente ao futuro e à importância de políticas de proteção do ambiente e de promoção da sustentabilidade, Abel defende uma maior fiscalização e mesmo a punição dos que transgridem. Reconhece que "o meio ambiente está a ser bem desenvolvido, mas ainda espero muito mais".

\subsection{Mário}

Mário tem 70 anos, é aposentado e tem discurso claro e sintético sobre o que é a sustentabilidade. Nas suas palavras, "A sustentabilidade é nós olharmos para uma melhor maneira de prevenir certos recursos disponíveis pelo planeta, para que estes continuem a existir nas gerações futuras".

Do seu ponto de vista, a sustentabilidade contribui enormemente para a qualidade do meio ambiente:

A sustentabilidade contribui para o melhoramento do meio ambiente, fazendo uma manutenção correta de, por exemplo, águas, resíduos, todas as matérias poluentes...; [...] é que realmente, se não corrigirmos, a médio ou longo prazo, estas medidas que se têm adotado... teremos uma maior poluição do planeta num futuro próximo, o que será prejudicial para as gerações futuras...

A propósito das suas práticas que considera sustentáveis, situa-se primeiro numa preocupação com a alimentação, com o uso equilibrado, para além da reciclagem que diz fazer: 
[...] tento alimentar-me à base de alimentos de produção própria [...], evito químicos... evito alimentos que sejam produzidos de pulverizações, poluentes que sejam nocivos para a saúde. Em relação aos restos, alguns utilizo para os animais [...], outros [...] são separados e colocados no lixo. [...]. Também utilizo a água com prudência [...], como a que recolho antes do banho, enquanto a água não vem quente; utilizo-as para as descargas do autoclismo, rega ou jardinagem.

[...] em relação à reciclagem, eu tento fazer [...] separação dos lixos para os respetivos contentores do plástico e do vidro [...], também faço reutilização [...] de materiais que já tinham pouca utilidade ou quase nenhuma, então aproveito e renovo alguns desses materiais, como móveis antigos [...].

[...] deixei de trazer tantos sacos de plástico quando vou às compras [...], porque utilizo os que já utilizei anteriormente, sacos grandes daqueles mais resistentes. Utilizo o mínimo de sacos de plástico possível [...].

Mário considera que hoje está mais limitado para poder implementar tudo o que defende como fundamental para diminuir a poluição e aumentar a sustentabilidade:

"[...] em relação a esse ponto, uma vez que hoje tenho pouca mobilidade, é mais complicado! Mas quando ainda conseguia caminhar e movimentar-me bem, deslocava-me o máximo possivel a pé... utilizava pouco o transporte para me deslocar aos sítios. Mas tenho noção que é um fator de poluição!".

Levado a pensar sobre a importância da aprendizagem de valores e práticas de sustentabilidade, vulgo educação para a sustentabilidade, não hesita em responder sobre o que parece já ter teoria própria resultante da observação e reflexão quotidianas: "[...] algumas foram práticas que eu trouxe da minha geração, e depois, consoante a evolução das gerações, outras práticas são reinventadas e aprendidas por mim". Quando pensa intergeracionalmente, defende que há já, hoje, um conhecimento profundo sobre a importância das práticas sustentáveis, mas que no futuro essa consciência e práticas terão de aumentar:

Temos de ter consciência de que, se não tivermos uma melhor maneira de prevenir certos abusos que aconteceram noutros tempos, e que ainda há nos dias de hoje, vamos sofrer - eu não, mas as gerações futuras vão sofrer ainda mais com os gastos excessivos; [...] é assim: as gerações mais antigas que a minha não tinham tanto conhecimento. Hoje em dia, na minha geração, nós já temos um médio conhecimento, e temos que realmente fazer ver às gerações futuras que eles têm de traçar um nível ainda maior e mais 
rigoroso para corrigir certos erros que há, porque senão será ainda mais complicado e prejudicial para as gerações vindouras.

No decurso das entrevistas/conversas, procurámos sempre levar a pensar sobre a importância das políticas públicas para a construção de um mundo mais sustentável. Também aqui, a partir dos seus 70 anos de vida, Mário mostra uma ideia muito própria sobre os passos que urge dar:

Contentores próprios para a prática de reciclagem seria realmente um passo em frente para as pessoas aceitarem mais e cumprirem mais, porque era uma maneira que eles tinham de fazer cumprir; os filhos e todas as pessoas que vivam na mesma casa, ao terem esses contentores disponiveis para a separação dos lixos, poderiam vir a cumprir muito mais. [...]. Se houvesse contentores mais distribuídos por famílias e lugares, as pessoas iam ter mais gosto em separar o lixo e acho iriam aderir muito mais [...]; [...] visto que se pagam os resíduos, nós pagamos sempre na fatura da água e da luz a taxa de resíduos, acho que se houvesse essa facilidade de podermos separar mais em casa seria ainda melhor.

Mário tem clara consciência da divergência entre o dizer e o fazer. Para si, [...] há sempre algo a aprendermos uns com os outros... Lembraria de que as medidas são boas, mas que têm de as tentar cumprir ao máximo... que tentem fazer realmente uma manutenção de todos os conselhos dados... cumpram e façam cumprir as normas e políticas estabelecidas... é muito importante... porque, efetivamente, vão-se colher os resultados mais tarde!

\section{EM BUSCA DE ALGUMAS CONCLUSÕES PRELIMINARES: ANÁLISE E COMPARAÇÃO DE NARRATIVAS E PONTOS DE VISTA}

Procedendo a uma análise comparativa das entrevistas realizadas, é percetível que, apesar das faixas etárias diferenciadas, todos os sujeitos apresentam preocupações relativamente à sustentabilidade, focando-se, essencialmente, na questão ambiental.

Apesar de aqui nos focarmos apenas no início do projeto, e tendo unicamente por base as entrevistas abertas, foi possível abordar tópicos e preocupações comuns às quatro gerações, sendo que todos (Brigite, Vera, Abel e Mário) expuseram um conhecimento reflexivo e prático com muitos denominadores comuns, assim como uma noção relativamente atualizada sobre o tema da sustentabilidade. Ainda assim, Brigite e Vera focaram mais práticas e reflexões menos abordadas, desenvolvidas 
pelo Abel e pelo Mário, designadamente as mais ligadas ao consumismo excessivo de carne, à opção de uma alimentação regida pelo veganismo e pelo vegetarianismo, e ao uso e compra exorbitante de roupa. Abel e Mário têm igualmente consciência da importância das práticas de sustentabilidade, mas resultantes talvez de uma vida sofrida e muito regrada, ligadas a uma sociedade com menos recursos, o que levou ao desenvolvimento de um maior sentido de poupança, de gestão da escassez e da reutilização sistemática de diversos materiais.

Parece haver alguma diferença de perspetivas face à relevância da educação para a sensibilização e consciencialização da importância das práticas de sustentabilidade. Ao longo das conversas realizadas, apenas foi verbalizada, por parte das estudantes, a importância da escola para a sensibilização, consciencialização e passagem de informação relativa à sustentabilidade, de modo a promover boas práticas de reutilização e de gestão equilibrada. Os mais velhos tendem a reforçar a educação geracional e a aprendizagem ao longo da vida, a tão referida "escola da vida", por parte do senso-comum.

No que toca à perspetiva política, todos os entrevistados consideram ser essencial a implementação de mais e melhores políticas em prol do ambiente, da qualidade de vida e da sustentabilidade. Importa perceber a necessidade de sensibilizar, consciencializar e educar para esta temática central da educação ambiental e social. Afinal, a sustentabilidade não é um tema que remete apenas para ambientalistas, ecologistas... Este é, cada vez mais, uma questão focalizada e pensada, também, a nível social, havendo maior discussão e reflexão públicas e também um interesse e responsabilidade por parte da escola e dos planos curriculares. A Educação Social poderá ter aqui um papel ainda mais visível, tanto na educação escolar como na educação fora da escola e ao longo de toda a vida. Poderá contribuir para toda esta (trans)formação a partir de novas propostas pedagógicas de educação ambiental e de promoção da educação para a mudança de comportamentos e mentalidades em relação ao desenvolvimento sustentável.

\section{REFERÊNCIAS}

BAKER, S. Sustainable development. London: Routledge, 2006.

BURGUESS, R. A pesquisa de terreno: uma introdução. Oeiras: Celta Editora, 1997. 
CONSELHO EMPRESARIAL PARA O DESENVOLVIMENTO SUSTENTÁVEL [BCSD]. Objetivos de desenvolvimento sustentável e o BCSD Portugal. ODS, Lisboa, 2021. Disponível em: https://www.ods.pt. Acesso em: 27 fev. 2021.

CRUTZEN, P. J.; STOERMER, E. F. The "anthropocene". Global Change NewsLetter, Stockholm, n. 41, p. 17-8, 2000.

DELORS, J. (Org.). Educação, um tesouro a descobrir: relatório para a UNESCO da comissão internacional sobre educação para o século XXI. Porto: Edições ASA, 1996.

DU PISANI, J. A. Sustainable development: historical roots of the concept. Environmental Sciences, [s.I.], v. 3, n. 2, p. 83-96, 2006.

FUNDO DAS NAÇÕES UNIDAS PARA A INFÂNCIA [UNICEF]. Objetivos de desenvolvimento sustentável: ainda é possível mudar 2030. Unicef, [s.I.], [s.d.]. Disponível em: https://www. unicef.org/brazil/objetivos-de-desenvolvimento-sustentavel. Acesso em: 27 fev. 2021.

MALTHUS, T. R. An essay on the principle of population as it affects the future improvement of society, with remarks on the speculations of Mr Godwin, M. Condorcet, and other writers. London: J. Johson, 1798.

SCHMIDT, L.; GUERRA, J. Do ambiente ao desenvolvimento sustentável: contextos e protagonistas da educação ambiental em Portugal. Revista Lusófona de Educação, Lisboa, v. 25, n. 25, p. 193-21, 2013.

SCHMIDT, L.; NAVE, J. G.; GUERRA, J. Educação ambiental: balanço e perspectivas para uma agenda mais sustentável. Lisboa: Imprensa de Ciências Sociais, 2010.

SUA PESQUISA. Sustentabilidade: saiba o que é sustentabilidade, conceito, desenvolvimento sustentável e gestão sustentável. Sua Pesquisa, São Paulo, 2021. Disponível em: https:// www.suapesquisa.com/ecologiasaude/sustentabilidade.htm. Acesso em: 27 fev. 2021.

TILBURY, D. Rising to the challenge: education for sustainability in Australia. Australian Journal of Environmental Education, Gold Coast, v. 20, n. 2, p. 103-14, 2004.

UNITED NATIONS [UN]. World Commission on Environment and Development. Report of the world commission on environment and development: our common future. [s.l.]: 1987. Disponivel em: https://sustainabledevelopment.un.org/content/documents/5987ourcommon-future.pdf. Acesso em: 18 maio 2021. 


\section{Sobre os autores:}

Ricardo Vieira: Agregado em Antropologia da Educação; pós-doutor em Serviço Social; e doutor em Antropologia Social pelo Instituto Superior de Ciências do Trabalho e da Empresa - Instituto Universitário de Lisboa (ISCTE-IUL). Mestre em Antropologia Cultural e Social; mestre em Sociologia da Cultura; e licenciado em Antropologia pela Universidade Nova de Lisboa. Atualmente é Professor Coordenador Principal no Instituto Politécnico de Leiria e Investigador Integrado do Centro Interdisciplinar de Ciências Sociais da Universidade Nova de Lisboa, polo de Leiria (CICS.NOVA.IPLeiria). E-mail: ricardo.vieira@ipleiria.pt, Orcid: https://orcid.org/0000-0003-1529-1296

Ana Maria Vieira: Doutora em Ciências da Educação; e mestre em História e Problemas Actuais da Educação pela Universidade de Trás-os-Montes e Alto Douro. Licenciada em Ensino Básico, variante de Matemática e Ciências da Natureza, pela Escola Superior de Educação e Ciências Sociais, Instituto Politécnico de Leiria. Atualmente é professora adjunta no Instituto Politécnico de Leiria. É coordenadora e investigadora integrada do Centro Interdisciplinar de Ciências Sociais da Universidade Nova de Lisboa, polo de Leiria (CICS.NOVA.IPLeiria). E-mail: ana.vieira@ipleiria.pt, Orcid: https://orcid.org/0000-0002-3976-6359

José Carlos Marques: Agregado em Sociologia pela Universidade Nova de Lisboa. Doutor em Sociologia pela Universidade de Coimbra. Mestre em Sociologia pela Universidade de Coimbra. Licenciado em Sociologia pela Universidade de Évora. Atualmente é Professor Coordenador Principal no Instituto Politécnico de Leiria. Investigador Integrado do Centro Interdisciplinar de Ciências Sociais da Universidade Nova de Lisboa, polo de Leiria (CICS.NOVA.IPLeiria). E-mail: jose.marques@ipleiria.pt, Orcid: https://orcid.org/0000-0002-4690-5943

\section{Recebido em: 12/03/2021}

Aprovado em: 22/05/2021 
